\title{
The Role of Inflammation in Cancer
}

\author{
O'Leary D.P., Neary P.M. and Redmond H.P. \\ Department of Academic Surgery, Cork University Hospital \\ Ireland
}

\section{Introduction}

Cancer is a pro-inflammatory disease. The link between inflammation and cancer was first noticed over 150 years ago. In 1863, Virchow observed that tumours tend to occur at sites of chronic inflammation (Balkwill, 2001).

Epidemiological studies have recently emerged which support the association between cancer and inflammation. Viruses and bacteria cause chronic inflammation and are significant risk factors in the development of malignancy. Human papilloma viruses, hepatitis B, hepatitis C and helicobacter pylori are well studied examples of this phenomenon which result in cervical cancer, hepatocellular cancer, lympho-proliferative disorders and gastric cancer respectively. Furthermore, increased risk of malignancy is associated with chronic inflammation caused by chemical and physical agents (Gulumian, 1999). In addition to epidemiological data, gene-cluster polymorphisms that lead to increased levels of pro-inflammatory cytokine release are associated with a poorer prognosis and disease severity in cancer patients (Warzocha, 1998; El-Omar, 2000). Moreover, the fact that chronic use of NSAIDs, such as aspirin are shown to reduce the incidence of numerous cancer types including colon, lung and stomach, gives additional supporting evidence for the link between inflammation and cancer (Wang, 2003).

\section{NF-kB - A key player}

Recent studies have implicated an inflammation-induced protein called nuclear factor kappa B (NF-kB) as a central figure in the link between cancer and inflammation. In 1986, Baltimore et al., originally discovered NF- $\mathrm{KB}$ as a factor in the nucleus of $\mathrm{B}$ cells that binds to the enhancer of the kappa light chain of immunoglobulin (Sen, 1986). NF- $\mathrm{KB}$ activity is considered a hallmark of inflammation. It is shown that NF-kB manipulation can convert inflammation-driven tumour growth into inflammation-induced tumour regression (Luo, 2004). Furthermore, many oncogenes and carcinogens can cause activation of NF-KB, whereas chemicals with chemo-protective properties can interfere with NF-kB activation (Bharti, 2002).

In unstimulated cells, the majority of NF-kB complexes are kept predominantly cytoplasmic and in an inactive form by binding a family of inhibitors known as Inhibitor- $\mathrm{kB}$ (ІкB). The NF-kB pathway can be activated by numerous stimuli including bacteria, viruses and proinflammatory cytokines especially tumour necrosis factor (TNF). Phosphorylation of NF-kB bound I-kappa-B kinases (IкK) on two conserved serine residues within the $\mathrm{N}$-terminal 
domain of the IкB proteins, which allows for proteasomal degradation and resultant NF-kB liberation. Activation of the NF- $\mathrm{kB}$ signalling cascade results in complete degradation of IKB allowing translocation of NF- $\mathrm{kB}$ to the nucleus where it induces transcription. The NF-kB family of transcription factors is composed of homodimers and heterodimers derived from 5 subunits - including REL-A(p65), c-REL, REL-B, p50(NF-kB1) and p52 (NF-kB2). When these subunits enter the nucleus, they can mediate transcription of target genes (Hayden, 2004). All family members share a highly conserved Rel homology domain responsible for DNA binding, dimerization domain and interaction with IкBs, the intracellular inhibitor of NF-кB. Cellular stresses including ionising radiation and chemotherapeutic agents can also activate NF-kB. The subsequent release of pro-inflammatory mediators (CSF-1, COX-2, IL-6, IL-1, VEGF, TNF) (Luo, 2004; Marx, 2004) and known anti-apoptotic regulators (BCL-2 and GADD45 $\beta$ ) are thought to potentiate tumour growth. In 2004, Karin et al discovered the mechanism that NF- $\mathrm{kB}$ contributes to tumourigenesis (Luo, 2004). Prior to this study evidence implicating NF- $\mathrm{kB}$ and cancer was mostly circumstantial. Using a murine model of colitis-associated cancer, researchers were able to use genetically altered mice which had the NF-kB activator enzyme IкK knocked out of intestinal epithelial cells and macrophages. In

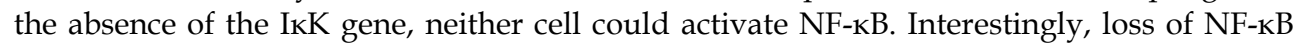
activity in both macrophages and epithelial cells individually reduced tumour incidence. They also found that this occurred through two different mechanisms. Tumour incidence decreased by approximately $50 \%$ with the loss of NF-KB activity in macrophages through a reduction in growth factors produced by inflammatory cells normally induced by NF- $\mathrm{KB}$ activation. Secondly, the loss of NF-kB activity in intestinal epithelial cells resulted in an $80 \%$ drop in tumour incidence. The mechanism seen here was different to that seen with the macrophages. Inflammation was not reduced as with the macrophages, instead, apoptosis was no longer inhibited in intestinal cells (Karin, 2004). Pikarsky et al had similar findings in a murine model of inflammation-associated liver cancer where they inhibited NF-KB by adding a gene encoding for IкB, a natural NF-кB inhibitor (Pikarsky, 2004).

The NF- $\mathrm{kB}$ family of transcription factors plays a key role in regulation of immune and inflammatory responses including apoptosis and oncogenesis (Baldwin, 2001). NF-kB regulated gene products including those encoding ICAM-1, the extracellular matrix protein tenascin C, vascular endothelial growth factor (VEGF), the chemokine IL-8, the proinflammatory enzyme COX2 and matrix metalloprotease 9 (MMP9) are associated with tumour progression and metastasis (Karin, 2002). However NF-kB may also control the expression of apoptosis promoting cytokines such as TNF alpha and FAS ligand (Kasibhatla, 1998).

NF- $\mathrm{kB}$ activation is required for endotoxin induced tumour growth. Lou et al showed both tumour nodule numbers and lung weights in the Lipopolysaccharide (LPS) challenged CT26 and CT26 vector groups were significantly higher than the controls $(<0.05)(\mathrm{Luo}, 2004)$. This demonstrates that inhibition of NF-kB activity in cancer cells converts the LPS-induced proliferative response to an apoptotic response. LPS was shown to induce NF-KB dependent genes in tumour cells. TNF alpha was shown to mediate LPS induced tumour growth and NF- $\mathrm{kB}$ activation. TRAIL mediates LPS induced regression of NF- $\mathrm{KB}$ deficient tumours. Overall, NF- $\mathrm{kB}$ in CT26 cells is responsible for induction of several anti-apoptotic proteins including Bcl-2 and Bcl-X. Most importantly the inhibition of NF-kB converted the growth promoting effect of LPS mediated by TNF alpha into a cytocidal effect. Trail is a weak inducer of inflammation which is an important characteristic, most likely related to its poor 
NF- $\mathrm{KB}$ activating ability. In addition to preventing the expression of anti-apoptotic proteins, inhibition of NF-kB also led to increased expression of the Trail receptor DR5. Type I and II interferons (IFN) are efficient inducers of Trail. The authors postulate that IFN based therapy with anti-TNF alpha medications may reduce inflammation associated toxicities, block inflammation induced tumour growth and potentiate Trail dependent tumour killing. The bcl-2 family of proto-oncogenes are a critical regulator of apoptosis and are frequently deregulated in a wide variety of cancers. They have recently been identified as having an NF-KB binding site in the bcl-2 p2 promoter (Catz, 2001). Thus chemotherapeutic drugs that activate NF- $\mathrm{KB}$ can also activate bcl-2 family proteins in various cancer cell lines. Activated $\mathrm{NF}-\mathrm{kB}$ binds to specific DNA sequences in target genes, designated as kB elements and regulates transcription of over 400 genes involved in immunoregulation, growth, inflammation, carcinogenesis and apoptosis.

Several chemotherapeutic agents including 5-fluorouracil (5-FU) have been reported to induce NF-KB activation in various cell lines (Cusack, 1999). Cytotoxic drugs induce NF-кB with delayed kinetics. This delay is due to the time required to induce nuclear DNA damage and relay the damage signal to the cytoplasmic IkK complex. Treatment with 5-FU can also induce activation of NF-KB in colorectal cancer cells (Wang, 2003). Using RKO human colorectal cell line and two NF-kB signalling deficient RKO mutants, Fukuyama et al demonstrated that 5-FU stimulates NF-KB and RKO cell survival through induction of IKK activity (Fukuyama, 2007). Several studies have shown that inhibition of NF-kB activation results in reversal of chemoresistance (Jones, 2000; Arlt, 2001; Cusack, 2001). It was shown that the inhibition of inducible NF- $\mathrm{kB}$ by a NF-KB decoy could induce apoptosis and reduce chemoresistance against 5-FU (Uetsuka, 2003). Inhibition of NF-kB activity reduces chemoresistance to 5-fluorouracil (5-FU) in human stomach cancer. Ionising radiation (IR) has been reported to activate NF-kB in both in vitro and in vivo studies (Rithidech, 2005; Ahmed, 2006). Laszlo et al recently reported that IkB-alpha depletion in the late phase of IR is a result of a combined regulation at both transcription and translation levels (Laszlo, 2008).

\section{Toll-like receptors}

\subsection{Overview}

Inflammation is initiated through many cellular transmembrane receptors of which the best characterised are the TLR family. Toll like receptors (TLRs) have been the subject of extensive investigation since their discovery in 1996. The first Toll receptor was discovered in Drosophila and it was revealed that the innate immune system may be activated once the receptor was bound by an extracellular ligand (Belvin, 1996). Subsequent research has revealed a total of 13 mammalian TLRs, 11 of which are expressed in humans. They are involved in the recognition by immune and non-immune cells of stimuli such as lipopolysaccharides (LPS) and dsRNA. They signal through the use of adapter proteins such as TRIF-related adaptor molecule (TRAF) and myeloid differentiation factor 88 (Myd88) (Killeen, 2009). Recognition of pathogen-associated molecular patterns (PAMPS) through TLRs, either alone or in heterodimerization with other TLRs or non-TLRs, triggers signals responsible for activation of the innate and adaptive immune responses. Most TLRs are found in innate immune cells such as polymorphonuclear neutrophils, monocytes/macrophages and dendritic cells where they trigger an immediate response. More recently TLRs have been shown to be expressed in a number of different cancer cells (Cheadle, 2002; Huang, 2008). Recent experimental evidence shows that TLRs display both 
tumouricidal and tumourigenesis properties (Salaun, 2006; Killeen, 2008). Each TLR recognises a different ligand. All TLRs (except for TLR3) signal through the adapter protein MyD88. MyD88 has been found to play a key role in inflammation induced tumour growth, principally through the innate immune system (Rakoff-Nahoum S, 2007). MyD88 mediates NF-kB activation through the canonical pathway (O'Neill, 2008; Akira, 2006). MyD88 is capable of NF-kB signalling selectively via TLR2 (Fitzgerald, 2003; Horng, 2001). Hence, both TLR2 and TLR4 both of which are expressed on the plasma membrane of cells appear to be involved in NF-kB inflammation-associated tumourigenesis. TLR2 is stimulated by numerous pro-inflammatory stimuli and helps activate the innate immune system.

Several TLRs are responsible for NF-kB activation. TLR4 induces tumour growth through NF- $\mathrm{KB}$ activation mediated by TNF- $\alpha$ (Luo, 2004). Interestingly, endotoxin or LPS, which binds specifically to TLR4 in cells is shown to be capable of inducing tumour growth (Pigeon, 1999). Endotoxin is a molecule found in the outer membrane of Gram-negative bacteria and elicits a strong inflammatory response in animals. Hence, it appears that the pro-tumorigenic effects of endotoxin occur through TLR4 mediated NF-kB activation. The focus of recent cancer immunology and medical oncology research has been aimed at activating the immune system in order to inhibit cancer cell growth and induce cancer cell apoptosis. Thus, TLRs offer a unique target for cancer therapy.

\subsection{Toll-like receptor-3}

TLR3 is a type 1 trans-membrane receptor protein located intracellularly on the endosome of eukaryotic cells. TLR3 has been shown to be an important "danger" signalling receptor that has a dual role in controlling the delicate balance between tolerance and inflammation on one hand and inflammation and disease on the other hand (Vercammen, 2008). TLR3 is composed of an ectodomain (ECD) containing multiple leucine rich repeats (LRRs), a transmembrane region and a cytoplasmic tail containing the Toll interleukin-1 receptor (TIR) domain (Vercammen, 2008). The LRRs form a horse shoe shaped solenoid structure which is capped at one end by a LRR N-terminal (LRR-NT) and the other end by a LRR Cterminal (LRR-CT) (Bell, 2005). The TLR3 ectodomain (ECD) binds dsRNA. This can only occur in an acidic environment $(\mathrm{pH}<6.5)$ reflecting the endosomal location of the receptor. DsRNA binding initiates a signalling pathway that recruits the TIR domain containing adaptor protein (TRIF) to its cytoplasmic domain. TLR3 is the sole TLR to interact directly with TRIF. The TIr domain of TLR3 then binds to TRIF. This indirectly activates several transcription factors including NFKB and IRF3. TRIF knockout mice have shown impaired Interferon-B production in response to a TLR3 ligand which proves that TRIF is essential to the signalling pathway (Takeuchi, 2003). TRIF is an adaptor molecule which is essential for TLR-3 signalling pathways (Yamamoto, 2003). The activity of TRIF allows indirect activation of several transcription factors such as NF-KB and IRF-3.

TLR3 is the critical sensor of the dsRNA. In response to dsRNA stimulation, specific signalling pathways are activated leading to activation of transcription factors such as nuclear factor- $\mathrm{\kappa B}(\mathrm{NF}-\mathrm{kB})$ and interferon regulatory factor 3 (IRF-3). This response acts as a defence mechanism against a viral insult to the body. The dsRNA itself is produced during viral replication (Jacobs, 1996). Strong or sustained TLR-3 signalling is potentially harmful and in some cases fatal to the host cell. It appears that the mammalian cells have adapted to this using a negative feedback mechanism. PIK3 and RIP-1 binding to TRIF has been shown to inhibit the actions of TRIF signalling (Meylan, 2004). Polyribosinic:polyriboctidic acid 
(poly I:C) is a stable synthetic dsRNA which acts as an agonist on the TLR3 receptor. It has been the subject of anti-cancer immunotherapy trials for decades. However its activity on the TLR3 receptor as well as RIG- 1 and MDA- 5 has only been recently identified. It activates the human innate system which subsequently regulates adaptive immunity. Poly I:C is recognised by both endosomal receptor TLR3 and cytosolic receptors including RNA helicases such as RIG-1 melanoma differentiation associated gene 5 (MDA5). TLR3 preferentially recognizes synthetic poly $(\mathrm{I}: \mathrm{C})$ rather than a virus derived dsRNA (Okahira, 2005). The important role played by TLR3 in poly I:C recognition was shown in one study which used TLR3 deficient mice. These mice demonstrated reduced responses to poly I:C and produced lower levels of inflammatory cytokines (Alexopoulou, 2001). Poly I:C has several side effects such as nephrotoxicity, coagulopathies and hypersensitivity reactions. In order to reduce this toxicity a modified form of poly I:C known as Poly I: $C_{12 U}$ has been produced. This substitutes uridine for cytosine at a ratio of 1:12 and results of a clinical trial of patients with HIV have proven Poly I: $\mathrm{C}_{12 \mathrm{u}}$ to be very safe. Studies using differing lengths of poly I:C showed that longer duplexes are better inducers of TLR3 signalling (Boone, 2004; Okahira, 2005). There are various alternatives to Poly I:C available. Poly $\mathrm{I}: \mathrm{C}_{12} \mathrm{U}$ is a mismatched dsRNA helix in which uridine has replaced cytosine. It has a rapid half-life compared to Poly I: $\mathrm{C}$ which has opened the door for its use as a clinically useful drug. Poly $\mathrm{I}: \mathrm{C}_{12} \mathrm{U}$ is more specific in its binding to TLR3 and this may account for its reduced toxicity and safe use in clinical trials (Mitchell, 2006). No evidence exists of dose limiting organ toxicity including haematological, liver or renal toxicity following intravenous administration to HIV positive patients (Thompson, 1996). Poly I:C mediates a potent adjuvant effect in cells expressing TLR3 and this strongly enhances antigen specific CD8+ Tcell responses, promotes antigen cross presentation by dendritic cells (Cui, 2006; Schulz, 2005) and directly acts on effector CD8 $+T$ and natural killer cells to alter the release of IFN- $\gamma$ (Tabiasco, 2006). It is the most potent type 1 interferon stimulant that is recognised by TLR3 (Yoneyama, 2004; Matsumoto, 2008).

TLR3 stimulation by dsRNA can cause direct apoptosis and inhibit cell proliferation in various types of cancer cells including colon, breast and melanoma (Taura, 2010; Salaun, 2006, 2007). It is now known that expression and function of TLR3 is dependent on p53 activation (Taura, 2008). Salaun et al recently used poly I:C to treat a breast cancer cell line by triggering apoptosis (Salaun, 2006). They showed that poly I:C can directly cause apoptosis without the involvement of the immune system. They also showed that poly I:C induced apoptosis occurred through the Fas-associated protein death domain-caspase 8 signalling pathway. The extrinsic apoptotic pathway was also shown to be involved by the same group in selected cancer cells (Salaun, 2007). Polyadenylic:polyuridylic acid (poly A:U) is another synthetic double stranded RNA. Poly A:U is unique as it only signals through TLR3. Poly A:U has been used with moderate success to treat breast and gastric cancer as a monotherapy (Laplanche, 2000; Jeung, 2010). Interferons (IFN) are a group of cytokines that can cause antiviral, antiproliferative and apoptotic effects through the Jak/STAT pathway signal transducers (Stark, 2007). In particular, IFN-a, a type I IFN has been shown to induce TLR3 expression and thus significantly enhance tumour cell apoptosis when combined with Poly I:C compared to each treatment alone (Taura 2010). The same study combined IFN-a, Poly I:C and 5-FU which resulted in a significant increase in cancer cell death in a colon cancer cell line. They also showed that by inhibiting the JAK/STAT pathway, induction of TLR3 by INF- a caused a reduced response of TLR3 to INF- a stimulation. Several clinical trials have examined the effect of combining a TLR3 agonist and INF- $\alpha$ with or without a 
chemotherapeutic agent. Wadler et al combined 5-FU with INF-a and achieved a good response in colon cancer cells however this combination was not effective in clinical trials (Wadler, 1990). Early clinical trials involving a TLR3 agonist as a single adjuvant therapy in colorectal cancer showed mixed results. Lacour et al showed that Poly A:U alone as an adjuvant therapy in colorectal cancer patients who had undergone a resection of the primary tumour was unable to improve the overall survival of patients after five years compared to a placebo (Lacour, 1992). However, when used as a combination therapy there have been very positive results in a clinical trial to demonstrate a positive role for Poly A:U in cancer treatment. After a 14 year median follow-up Laplanche et al reported the results of a trial which combined Poly A:U with loco-regional radiotherapy versus chemotherapy with cyclophosphamide, methotrexate and fluorouracil (CMF) in women with operable breast cancer. They reported that the Poly A:U combination group had a significantly improved disease free survival $(p=0.03)$ and significantly reduced the incidence of metastasis when compared to the CMF group. This trial did not however differentiate the role that Poly A:U and radiotherapy had as single therapies (Laplanche, 2000). Several studies have reported that caspase 3 is up-regulated by TLR3 agonist activity which would suggest a role for caspase 3 in cancer cell apoptosis induced by TLR3 agonists (Salaun, 2006; Khvalevsky, 2007). A recent study by Conforti et al demonstrated the synergistic effects between vaccines, chemotherapy and poly A:U (Conforti, 2010). A vaccine (OVA plus CpG) was administered prior to the combination of oxaliplatin and poly A:U and this significantly reduced tumour growth and prolonged survival. Interestingly these results were not demonstrated in nude and TRIF knockout mice.

\subsection{Toll-like receptor-4}

TLR4 was first discovered in 1998. Lipopolysaccharide (LPS) is a cell wall protein in gram negative bacteria and works as a ligand for TLR4. The recognition of LPS by TLR4 requires other proteins including LPS binding protein, CD14 and MD2. In resting cells TLR4 is located in the Golgi apparatus. The translocation of TLR4 from the Golgi apparatus to the plasma membrane and the binding of LPS is dependent on MD2 (Nagai, 2002; Shimazu, 1999). TLR4 signals through two pathways: the MyD88-dependant pathway and the MyD88-independant pathway. In the MyD88-dependant pathway, MyD88 binds to the TollIL-1 receptor domain of the TLR4 receptor and activates IL-1 receptor associated kinase (IRAK). IRAK in turn phosphorylates TRAF6, which in turn activates a MAP-3-kinase called TAK1, and TAK1 phosphorylates and activates the IKK complex. IкK then liberates NFKB. Killeen et al showed that bacterial endotoxins directly promote tumour cell adhesion and invasion through up-regulation of urokinase plasminogen activator and urokinase plasminogen activator receptor through TLR4 dependant activation of $\mathrm{NF}_{\mathrm{K}} \mathrm{B}$ (Killeen 2009). TLR4 can also signal through the MyD88-independant pathway to stimulate the production of Interferon-B. Wang et al showed that TLR4/MyD88 over-expression was frequently detected in colo-rectal cancer with liver metastasis and TLR4/MyD88 levels were significantly higher in these patients (Wang, 2010). Although there have been a number of studies investigating the role of TLR4 in colo-rectal cancer, the exact impact of TLR4 signalling in comparison to TLR3 signalling in colon cancer cells has yet to be established. TLR4 signalling has been shown to promote resistance of cancer cells to apoptosis following introduction of a TLR4 ligand in colon cancer cells (Cianchi, 2010). TLR4 signalling appears to promote the development of colitis associated cancer by mechanisms including enhanced 
Cox-2 expression and increased EGFR signalling (Fukata, 2007). Recent experimental studies have shown that TLR4 induced inflammatory factors may cause tumour cell escape from immune surveillance and resistance to chemotherapy and radiotherapy (He, 2007).

One proposed mechanism by which tumour cells resist treatment involves an impairment of the immune response by the inflammatory microenvironment at the tumour site (Coussens, 2002). TLR4 upregulation has been shown to increase the secretion of immunosuppressive cytokines TGF- $\beta$, VEGF and pro-angiogenic chemokine IL-8 in human lung cancer cells and induces resistance of human lung cancer cells to TNF- $\alpha$ and TRAIL induced apoptosis (He, 2007). The same study demonstrated secretion of VEGF and IL-8 is p38MAPK dependent and the ERK1/2 and JNK1/2 proteins are not activated. NF-KB activation contributes to apoptosis resistance of human lung cancer cells after LPS stimulation and LPS-induced apoptosis is dependent on NF-kB activation in human lung cancer cells. NF-kB is an antiapoptotic transcriptional factor induced by cellular components such as LPS, radiation and various chemotherapy drugs.

Contrasting evidence for the role of TLR4 in chemotherapy and radiotherapy resistance was reported by Apetoh et al who demonstrated reduced tumour growth and prolonged survival in immunocompetent wild type mice when treated with chemotherapeutic agents such as oxaliplatin and doxorubicin but this effect was significantly less in TLR4-/- mice and $\mathrm{nu} / \mathrm{nu}$ mice (Apetoh, 2007). These findings were also demonstrated in TRIF-/- mice which behaved like the wild type mice but Myd88/- mice behaved like TLR-/-mice. This suggests a certain dependence of tumour treatment resistance on the MyD88 dependent pathway in TLR4 signalling. These results show that when TLR4 itself is knocked out this will lead to a reduction in tumour growth when the tumour is exposed to an appropriate chemotherapeutic agent or radiotherapy. However, when TLR4 is up regulated in the presence of LPS, this results in resistance to chemotherapy and arguably radiotherapy treatment.

Various agents have been suggested as having a role in reversing TLR4 induced tumour apoptotic resistance. Rapamycin is one such agent. Rapamycin is a macrolide antifungal agent and is a potent immunosuppressive medication that is used as an anti-inflammatory and immunosuppressive drug for the treatment of autoimmune diseases such as Systemic lupus erythematosus (SLE) and transplantation rejection (Fernandez, 2006; Hackstein, 2003). In terms of cancer treatment Rapamycin has been shown to display a number of useful anticancer cell properties including inhibition of cancer cell proliferation and induction of apoptosis (Hartford, 2007; Zhang, 2007). Rapamycin can also inhibit invasion and metastasis of tumour cells (Abraham, 2007). One study focused on Rapamycins ability to reverse the apoptotic resistance that can occur following TLR4 stimulation with LPS. Sun et al showed that Rapamycin reverses TLR4 ligation induced apoptotic resistance in colon cancer cells (Sun, 2008). Interestingly this same study showed that Rapamycin inhibits anti-apoptotic protein bcl-xL expression and activation of Akt and NF-kB pathways following LPS treatment of cells and this was shown to reverse apoptosis when Akt and NF- $\mathrm{kB}$ were inhibited. Paclitaxel has been described as a potential ligand to TLR4 (Asselin, 2001). Kelly et al demonstrated that TLR4 signalling promotes tumour growth and paclitaxel chemoresistance in ovarian cancer cells (Kelly, 2006). This behaviour was mediated by MyD88 expression. 


\section{Role of chemokines and cytokines}

\subsection{Overview}

Both TLR3 and TLR4 signalling produce a pro-inflammatory response including chemokines and it has previously been shown that the pro-inflammatory response may contribute to tumorigenesis (Kelly, 2006). Chemokines and cytokines are markers of inflammation which normally recruit leucocytes and aid in blood vessel remodelling. Pathophysiological roles for chemokines include acting as autocrine growth factors, disruption of basement membranes, increasing motility and tumour invasion (Rollins, 2006; Balkwill 2004).

\subsection{CXCL-8/IL-8}

A recent paper examined the presence of cytokines, chemokines and their receptors in colon cancer using a Taqman Low Density Array with probes for 24 ligands and 17 receptors. This revealed CCL3, CCL4 and CXCL8 levels to be significantly increased in colon cancer samples compared to normal tissue (Erreni, 2009). Further analysis of the levels of CCL3, CCL4 and CXCL8 mRNA expression showed that CCL4 and CCL3 levels were higher in normal and tumour tissue. However, CXCL8 expression was significantly increased in tumour tissue $(\mathrm{p}<0.0001)$. There was no correlation with tumour stage for all three inflammatory markers. SW620 and HT29 cell lines showed low but detectable levels of CXCL8 which increased with stimulation with TNFa and TGF $\beta$. Interestingly there was high levels of two anti-angiogenic chemokines found in these samples also, CXCL9 and CXCL10 but their receptor was not significantly expressed.

The main function of CXCL8 is the recruitment of neutrophils. These leucocytes have a short life span and have no presence or role in the tumour micro-environment. CXCL8 has however been reported to have a role in the tumour micro-environment by stimulating tumour advancement and invasion by stimulating the process of neoangiogenesis and by activating tumour matrix proteases (Zhu, 2004; Bates, 2004). However, CCL3 and CCL4 are not products of TLR3 and TLR4 signalling, but CXCL8 is produced as a result of signalling by TLR3 and TLR4. Elevated levels of CXCL8 or Interleukin- 8 has been associated with increased angiogenesis in normal and transformed tissue adjacent to colon cancer tumours (Fox, 1998; Kuniyasi, 2000). Also, increased CXCL8 protein expression in primary colo-rectal tumours increases the risk of metastasis (Haraguchi, 2002). To date CXCL8 has two known receptors, CXCR1 and CXCR2. These receptors are known broadly as G-protein coupled receptors (GPCR). Recently GPCR antagonists have been developed which can block the biological effects of GPCR signalling. [D-Arg1, D-Trp ${ }^{5,7,9}$, Leu $^{11}$ ]SP or substance P antagonist is a potent GPCR antagonist and has been shown to inhibit small cell lung cancer cell proliferation both in vitro and in vivo (Seckl, 1997) and in pancreatic cancer cell proliferation in vitro and in vivo (Guha, 2005). The GPCR ligand/receptor interaction has been shown to result in neuropeptide-induced $\mathrm{Ca}^{2+}$ mobilisation which increases intra-cellular $\mathrm{Ca}^{2+}$ and this proves useful as a marker of GPCR function (Ryder, 2001). A GPCR antagonist has previously been shown to prevent GPCR agonist induced increase in $\mathrm{Ca}^{2+}$, DNA synthesis and anchorage independent growth in pancreatic cancer cells (Guha, 2005). The role of a GPCR antagonist in colon cancer has yet to be established. IL-8 is produced and has been shown to be produced by tumour cells and the level of its production correlates directly with the metastatic potential of the tumour (Abdollahi, 2003; Bruserud, 2004). 


\section{Immuno-surveillance}

The interaction between cancer cells and the innate and adaptive immune system is complex. As described previously, pro-inflammatory cytokines promote tumour growth; however the immune system has a means of restricting cancer development through immuno-surveillance and immuno-editing. The pro-tumorigenic effect of the inflammatory immune response appears generally to be a consequence of the innate immune system, whereas the adaptive immune system exerts anti-tumorigenic effects (Karin, 2005).

Cancer immunosurveillance is a theory formulated in 1957 by Burnet and Thomas, who proposed that lymphocytes act as sentinels in recognising and eliminating continuously arising transformed cells (Dunn, 2002; Burnet, 1957). Cancer immunosurveillance appears to be an important host protection process that inhibits carcinogenesis and maintains regular cellular homeostasis (Kim 2007). It has been shown that when mice are deficient in genes that encode for cells integral to the adaptive immune response such as T cells, B cells and natural killer $\mathrm{T}$ (NKT) cells, tumour incidence and tumour growth are increased (Shankaran, 2001). With the aid of additional studies, natural killer cells and T cells now appear to be the dominant cells involved in tumour immuno-surveillance. Interestingly, interferon- $\gamma$ (IFN- $\gamma$ ) is produced by both NKT and T cells. Furthermore, IFN- $\gamma$ is the most influential cytokine released by these cells. Recent studies have now shown that mice deficient in IFN- $\gamma$ are more susceptible to spontaneous carcinogenesis (Shankaran, 2001).

The mechanism involved in the anticancer protective effect of the immune system is complex. Generally, it is theorised that cells of the immune system recognise the presence of a growing tumour which has undergone stromal remodelling, causing local tissue damage. This is followed by the induction of inflammatory signals which recruits natural killer cells, NKT cells and macrophages to the tumour site. During this phase, the infiltrating lymphocytes such as the natural killer cells and NKT cells are stimulated to produce IFN-ץ. Newly synthesised IFN- $\gamma$ then induces tumour death as well as promoting the production of chemokines which play an important role in promoting tumour death by blocking the formation of new blood vessels.

Similarly, IL-4 is released in large quantities by NKT cells upon activation and is a key regulator in the adaptive immunity. Therapeutic attempts to recruit the immune system to curtail cancer growth have now become a keen area of interest. Although, attempts have met with limited success thus far, this is the basis of vaccine guided anti-cancer therapy which is a rapidly progressing area of research (Dranoff, 2004).

It is clear that elements of the immune system can restrict tumour growth. However, as discussed previously pro-inflammatory cytokine release initiated by the immune system can also promote tumour growth. Therefore, the immune system appears to have the effect of a double edged sword on cancer growth. If we had full understanding and control of these pathways, this could potentially lead to successful cures for cancer.

\subsection{Vaccines}

Recently vaccines have been developed to take advantage of the role played by the immune system in cancer. The discovery of tumour associated antigens (TAA) expressed by colorectal carcinoma as well as recent advances in tumour immunology are providing new focus to develop biologically targeted immunotherapeutic strategies. It has been reported that immuno-deficient animals as well as humans, e.g. transplant patients, are at greater risk of developing malignancy (Penn, 2000). It has also been reported that cytotoxic $\mathrm{T}$ 
lymphocytes (CTL) and antibodies specific for TAA have been demonstrated in patients with cancers including colorectal cancer (Nagorsen, 2000). Therefore there is an ideal niche in cancer treatment for an active specific immunotherapy. Previously identified or undefined TAAs can be administered to cancer patients in order to cause a systemic immune response which will lead to malignant cell destruction (Rosenberg, 2001).

Despite the huge amount of evidence and theoretical potential of this treatment strategy, the clinical results are limited to date. There is evidence to support the tumouricidal effects of active specific immunotherapy however it appears cancer cells are able to survive the tumouricidal effects as the disease progresses. This phenomenon has become known as 'tumour immune escape'. Several mechanisms have been proposed as to how this phenomenon occurs. One body of evidence shows evidence that cancer genetic instability leads to TAA/HLA downregulation as well as to disruption of the TAA processing/presenting machinery which then allows malignant cells to evade the surveillance of immune sentinels (Seliger, 2001; Yang, 2003). Another proposed mechanism lies in the ability of cancer cells to produce immunosuppressive cytokines e.g. IL-10, and thus counteract the immune system response (Mocellin, 2001; Walker, 1997). The challenge for tumour immunologists currently is to overcome this 'tumour immune escape' and increase the proportion of patients mounting an immune response and increase the rate of responses from the targeted tumour.

The role of macrophages in the development of colorectal cancer is controversial. One study demonstrated that increased numbers of macrophages in all areas of the tumour correlated with an advanced tumour stage (Bailey, 2007). On the other hand Forssell et al showed that the presence of macrophages positively influenced prognosis in colorectal cancer (Forssell, 2007). Another group demonstrated that macrophages have the ability to inhibit or stimulate tumour growth according to their polarisation and state of activation (Mantovani, 2005). This group showed that M1-polarised macrophages activated by IFN $\gamma$ and bacterial products like LPS display tumouricidal effects whereas M2 macrophages differentiated in the presence of Th2 cytokines, IL-4, IL-13 or IL-10, have the opposite effect. These macrophages favour tumour cell proliferation and stimulate tumour progression and tumour invasion. These studies are crucial in demonstrating the important role that inflammatory mediators such as chemokines and cytokines play in the establishment of the tumour microenvironment. The tumorgenicity of proinflammatory mediators such as interleukin- 6 and tumour necrosis factor- $\alpha$ (TNFa) was shown by Coussens et al (Coussens, 2002).

\section{Surgery, inflammation and tumourigenesis}

At present, the only recognised curative treatment for cancer is surgery. As a result, surgery is the mainstay treatment for tumours. However, surgery is not indicated for all patients with a cancer diagnosis. Surgery is only indicated in these patients if the cancer has not dissipated and spread to distant organs. In fact, surgery in these patients worsens outcome and survival. This begs the question, is surgery tumorigenic? Numerous studies have examined the role of surgery itself on tumour growth. Interestingly, cancer surgery in the presence of micrometastases increases metastatic burden and enhances peri-operative tumour growth (Pigeon, 1999; MS, 1997; Coffey, 2002). The presence of undetected micrometastases is thought to be largely responsible for these recurrences. Cancer patients often harbour micrometastases which are undetectable at the time of surgery. Surgical 
intervention in these patients is thought not only to accelerate their progression but also to be responsible for activating dormant micrometastases that may have remained inactive in the absence of surgery. In addition, the extent of the surgery is proportional to the postoperative recurrence rate. This is evidenced by the meta-analyses that show that minimally invasive surgery is more effective than open surgery in improving tumour recurrence, and cancer-related survival (Hensler, 1997), although equally studies exist that do not support this idea (Jayne, 2010). Considering surgery is the only curative treatment of solid tumours, this knowledge has prompted efforts to understand this undesired effect of surgery. It is hoped that this understanding will eventually help develop therapeutic treatments that may attenuate or eliminate this unwelcome consequence of surgery.

\subsection{Mechanisms of surgery induced tumourigenesis}

Considering what is already known concerning the role of inflammation in tumourigenesis, it is not surprising that surgery is tumorigenic. Surgery confers a traumatic insult to the body which like all traumas induce a potent pro-inflammatory response. Surgery is followed by a biologic period of repair to help restore homeostasis. It induces an early hyper-inflammatory response, which is characterised by pro-inflammatory TNF-a, IL-1 and IL-6 cytokine release (Walker, 1999) and neutrophil activation (Hensler, 1997). Several of these cytokines have been shown to potentiate tumour growth (Coussens, 2004). The massive and continuous IL-6 release subsequently accounts for the up-regulation of major anti-inflammatory mediators, such as $\mathrm{PGE}_{2}$, IL-10, and TGF-ß (Walker 1999). The magnitude and duration of this hyper-inflammatory response is proportional to the severity of the trauma which may explain how laparoscopic versus open surgery may result in lower tumour recurrence (Colacchio, 1994; Baigrie, 1992). Following surgery, angiogenesis is also stimulated as the body initiates a period of healing and biological repair. Pro-angiogenic substances such as VEGF become elevated post-operatively. Moreover, anti-angiogenic substances such as endostatin and angiostatin are not detectable in the serum shortly after tumour excision (Li, 2001; Holmgren 1995; O'Reilly, 1994). This incites the formation of capillaries and new blood vessels not only to the areas of tissue insult but also to all parts of the body including areas of residual metastatic disease which promotes tumour growth.

Furthermore, surgery also influences immune system function. Immuno-suppression is a feature of the post-operative stress response and is also associated with anaesthesia, blood transfusion and the release of acute-phase proteins (Lee, 1977). The immune system appears to be an important regulator in identifying and eliminating any abnormal cells with cancerous potential. Hence, any disruption of immune function as a result of surgery can also lead to potentiating tumour growth. Interestingly, this immuno-suppression is greater dependent on the extent of surgery (Da Costa, 1998; Da Costa, 1999). The immunosuppressive effects of surgery can last anywhere from between 4 to 14 days depending on the size of surgical trauma induced but peaks day three post-operatively in most cases. Likewise, this may explain why laparoscopic versus open surgery in colon cancer patients confers a greater survival advantage, although the evidence supporting this is not equivocal.

Endotoxaemia also occurs following surgery involving bowel manipulation. Endotoxin, a potent inflammatory mediator, is a component on the wall of Gram negative bacteria often found in the lumen of the gastrointestinal system. Upon manipulation, endotoxin or LPS translocates across the intestinal lumen and enters the circulation. Endotoxaemia further 
potentiates the hyper-inflammatory response following surgery such as colorectal cancer resection. One study examined the effect of endotoxin administration on a murine breast cancer model (Pigeon, 1999). Interestingly, they found enhanced metastatic growth in the endotoxin treated group compared to controls. In a later study the same group found that endotoxin-induced metastatic growth was associated with increased angiogenesis, vascular permeability and tumour cell invasion and migration (Harmey, 2002). Therefore, this is another potential mechanism of surgically induced tumour growth especially in regard to colorectal cancer operations. In addition, the actual manipulation of the tumour during surgery results in the dissemination of tumour cells into the circulation. These tumour cells can potentially seed in distant sites throughout the body facilitating metastatic spread. Surgeons will make efforts to minimise tumour manipulation intra-operatively to minimise this potential.

Peri-operative tumour growth appears to significantly impact on tumour recurrence following "curative" surgery. Following a deeper understanding of this mechanism, therapeutic efforts are now being sought. Peri-operative immunomodulators such as IL-2, known to abrogate the immune changes that follow excisional cancer surgery, are being investigated as potential peri-operative treatments showing promising initial results (Den Otter, 1996). Even current chemotherapeutic regimes known to induce cell death in rapidly dividing cells have been given immediately post-operatively resulting in increased longterm survival. However, most of these treatments are limited by their toxicities as tissue and wound healing are essential in the immediate post-operative period.

\section{Conclusion}

Overall, our understanding of the relationship between inflammation and cancer has improved greatly since Virchow first made his observation over 150 years ago. The unravelling of signalling pathways shared by cancer and inflammation will provide the focus for future cancer treatment strategies.

\section{References}

Abdollahi T, Robertson NM, Abdollahi A, Litwack G. 2003. Identification of interleukin 8 as an inhibitor of tumor necrosis factor-related apoptosis-inducing ligand-induced apoptosis in the ovarian carcinoma cell line OVCAR3. Cancer Res. 63, 4521-4526.

Abraham RT, Gibbons JJ. The mammalian target of rapamycin signaling pathway: twists and turns in the road to cancer therapy. Clin Cancer Res 2007;13:3109-14.

Ahmed KM, Dong S, Fan M, Li JJ. Nuclear factor-kappaB p65 inhibits mitogen activated protein kinase signaling pathway in radioresistant breast cancer cells. Mol. Cancer Res. 4 (2006) 945-955

Akira S, Uematsu S, Takeuchi O. Pathogen recognition and innate immunity. Cell 2006;124(4):783-801.

Alexopoulou, L., A. C. Holt, R. Medzhitov, and R. A. Flavell. 2001. Recognition of doublestranded RNA and activation of NF-kB by Toll-like receptor 3. Nature 413:732-738.

Apetoh L, Ghiringhelli F, Tesniere A. Toll-like receptor 4-dependent contribution of the immune system to anticancer chemotherapy and radiotherapy. Nature Medicine. 2007;13(9):1050-1059. 
Arlt A, Vorndamm J, Breitenbroich M, Folsch UR, Kalthoff H, Schmidt WE, Schafer H. Inhibition of NF-kappaB sensitizes human pancreatic carcinoma cells to apoptosis induced by etoposide (VP16) or doxorubicin, Oncogene 20 (2001) 859-868.

Asselin E, Mills GB, Tsang BK. XIAP regulates Akt activity and caspase-3-dependent cleavage during cisplatin-induced apoptosis in human ovarian epithelial cancer cells. Cancer Res 2001;61:1862-8.

Baigrie R, Lamont P, Kwiatkowski D, Dallman M, Morris P. Systemic cytokine response after major surgery. British Journal of Surgery 1992;79(8): 757-760.

Bailey C, Negus R, Morris A, Ziprin P, Goldin R et al. Chemokine expression is associated with the accumulation of tumour associated macrophages (TAMs) and progression in human colorectal cancer, Clin. Exp. Metastasis 24 (2007), pp. 121-130

Baldwin, A.S., Jr. (2001). Series introduction: The transcription factor NF-B and human disease. J. Clin. Invest. 107, 3-6.

Balkwill F, Mantovani A. Inflammation and cancer: back to Virchow? The Lancet 2001;357(9255): 539-545.

Balkwill F. Cancer and the Chemokine Network. Nature Reviews, Cancer 2004;4:540-50.

Bates RC, DeLeo MJ, Arthur M. The epithelial-mesenchymal transition of colon carcinoma involves expression of IL-8 and CXCR-1-mediated chemotaxis. Mercurio Experimental Cell Research 299 (2004) 315- 324.

Baud V, Karin M. Is NF-kappaB a good target for cancer therapy? Hopes and pitfalls, Nat. Rev. Drug Discov. 8 (2009) 33-40

Bell JK. Proc. Natl. Acad. Sci. U.S.A. 102, 10976 (2005).

Belvin MP, Anderson KV. A CONSERVED SIGNALING PATHWAY: The Drosophila TollDorsal Pathway. Annual Review Cell Dev. Biol. 1996. 12:393-416

Bharti AC AB. Chemopreventive agents induce suppression of nuclear factor-kappaB leading to chemosensitization. Ann N Y Acad Sci 2002;973(Nov): 392-395.

Böhm B, Schwenk W, Hucke H, Stock W. Does methodic long-term follow-up affect survival after curative resection of colorectal carcinoma? Diseases of the Colon \& Rectum 1993;36(3): 280-286.

Boone DL, Turer EE, Lee EG, Ahmad RC, Wheeler MT et al. 2004. The ubiquitin-modifying enzyme A20 is required for termination of Toll-like receptor responses. Nat. Immunol.5:1052-1060.

Braumann C, Winkler G, Rogalla P, Menenakos C, Jacobi C. Prevention of disease progression in a patient with a gastric cancer-re-recurrence. Outcome after intravenous treatment with the novel antineoplastic agent taurolidine. Report of a case. World Journal of Surgical Oncology 2006;4(1): 34.

Bruserud O, Ryningen A, Wergeland L, Glenjen NI, Gjertsen BT. 2004. Osteoblasts increase proliferation and release of pro-angiogenic interleukin 8 by native human acute myelogenous leukemia blasts. Haematologica 89, 391-402.

Burnet F. Cancer-A biological approach. 37. Med J 1957;1: 779-841.

Catz SD, Johnson JL, Transcriptional regulation of bcl-2 by nuclear factor kappa B and its significance in prostate cancer, Oncogene 20 (2001) 7342-7351.

Cheadle EJ, Jackson AM. (2002) Bugs as drugs for cancer. Immunology 107:10-19

Coffey J, Doyle M, O'Mahony L. Probiotics confer protection against perioperative metastatic tumour growth. Ann Surg Oncol 2002;9: 93. 
Colacchio T, Yeager M, Hildebrandt L. Perioperative immunomodulation in cancer surgery. American journal of surgery 1994;167(1): 174

Conforti R, Ma Y, Morel Y, Paturel C, Terme M, Viaud S, Ryffel B, Ferrantini M, Uppaluri R, Schreiber R, Combadière C, Chaput N, André F, Kroemer G, Zitvogel L. Opposing effects of toll-like receptor (TLR3) signaling in tumors can be therapeutically uncoupled to optimize the anticancer efficacy of TLR3 ligands. Cancer Res. 2010 Jan 15;70(2):490-500.

Coussens L. Inflammation and cancer. Toxicologic Pathology 2004;32(6): 732-734.

Coussens LM, Werb Z. Inflammation and cancer. Nature 2002; 420: 860-66.

Cui Z, Qiu F. Synthetic double-stranded RNA poly(I:C) as a potent peptide vaccine adjuvant: therapeutic activity against human cervical cancer in a rodent model. Cancer Immunol Immunother 2006;55: 1267-79.

Cusack JC, Liu R, Baldwin AS. NF- kappa B and chemoresistance: potentiation of cancer drugs via inhibition of NF- kappa B, Drug Resist. Updat. 2 (1999) 271-273

Cusack JC, Liu R, Houston M, Abendroth K, Elliott PJ, Adams J, Baldwin AS. Enhanced chemosensitivity to CPT-11 with proteasome inhibitor PS-341: implications for systemic nuclear factor-kappaB inhibition, Cancer Res. 61(2001) 3535-3540.

Da Costa M, Redmond H, Bouchier-Hayes D. The effect of laparotomy and laparoscopy on the establishment of spontaneous tumor metastases. The Journal of Urology 1999;162(2): 633-634.

Da Costa M, Redmond H, Finnegan N, Flynn M, Bouchier-Hayes D. Laparotomy and laparoscopy differentially accelerate experimental flank tumour growth. British Journal of Surgery 1998;85(10).

Den Otter W, De Groot J, Bernsen M, Heintz A, Maas R, Jan Hordijk G, Hill F, Klein W, Ruitenberg E, Rutten V. Optimal regimes for local IL-2 tumour therapy. International Journal of Cancer 1996;66(3).

Dranoff G. Cytokines in cancer pathogenesis and cancer therapy. Nature Reviews Cancer 2004;4(1): 11-22.

Dunn G, Bruce A, Ikeda H, Old L, Schreiber R. Cancer immunoediting: from immunosurveillance to tumor escape. Nature immunology 2002;3(11): 991-998.

Erreni M, Bianchi P, Laghi L, Mirolo M, Fabbri M et al. Expression of Chemokines and Chemokine Receptors in Human Colon Cancer Methods in Enzymology, Volume 460, 2009, Pages 105-121.

Fernandez D, Bonilla E, Mirza N, Niland B, Perl A. Rapamycin reduces disease activity and normalizes $\mathrm{T}$ cell activation-induced calcium fluxing in patients with systemic lupus erythematosus. Arthritis Rheum 2006;54:2983-8.

Fitzgerald KA, McWhirter SM, Faia KL, Rowe DC, Latz E, Golenbock DT, Coyle AJ, Liao SM, Maniatis T. IKK\&epsi; and TBK1 are essential components of the IRF3 signaling pathway. Nature immunology 2003;4(5): 491-496.

Forssell J, Oberg A, Henriksson ML, Stenling R, Jung A, Palmqvist R. High macrophage infiltration along the tumor front correlates with improved survival in colon cancer, Clin. Cancer Res. 13 (2007), pp. 1472-1479

Fox SH, Whalen GF, Sanders MM, Burleson JA, Jennings K, Kurtzman S, Kreutzer D. Angiogenesis in normal tissue adjacent to colon cancer. Journal of Surgical Oncology 1998;69:230-4. 
Fukata M, Chen A, Vamadevan AS, Cohen J, Breglio K, Krishnareddy S, Hsu D, Xu R, Harpaz N, Dannenberg AJ, Subbaramaiah K, Cooper HS, Itzkowitz SH, Abreu MT (2007) Toll-like receptor-4 promotes the development of colitis-associated colorectal tumors. Gastroenterology 133: 1869-1881.

Fukuyama R, Ng KP, Cicek M, Kelleher C, Niculaita R, Casey G, Sizemore N. Role of IKK and oscillatory NFkappaB kinetics in MMP-9 gene expression and chemoresistance to 5-fluorouracil in RKO colorectal cancer cells, Mol. Carcinog. 46 (2007) 402-413.

Guha S, Eibl G, Kisfalvi K, Fan R, Burdick M. Broad-Spectrum G Protein-Coupled Receptor Antagonist, [D-Arg1,D-Trp5,7,9,Leu11]SP: A Dual Inhibitor of Growth and Angiogenesis in Pancreatic Cancer. Cancer Res April 1, 2005 65; 2738.

Gulumian M. The role of oxidative stress in diseases caused by mineral dusts and fibres: current status and future of prophylaxis and treatment. Molecular and cellular biochemistry 1999;196(1): 69-77.

Hackstein H, Taner T, Zahorchak AF, Morelli AE, Logar AJ, Gessner A, et al. Rapamycin inhibits IL-4-induced dendritic cell maturation in vitro and dendritic cell mobilization and function in vivo. Blood 2003;101:4457-63.

Haraguchi M, Komuta K, Akashi A, Matsuzzaki S, Furui J, Kanematsu T. Elevated IL-8 levels in the drainage vein of resectable Duke's C colorectal cancer indicate high risk for developing hepatic metastasis. Oncology Reports 2002;9:159-65.

Harmey J, Bucana C, Lu W, Byrne A, McDonnell S, Lynch C, Bouchier-Hayes D, Dong Z. Lipopolysaccharide-induced metastatic growth is associated with increased angiogenesis, vascular permeability and tumor cell invasion. International Journal of Cancer 2002;101(5): 415-422.

Hartford CM, Ratain MJ. Rapamycin: something old, something new, sometimes borrowed and now renewed. Clin Pharmacol Ther 2007;82:381-8.

Hayden MS, Ghosh S. Signaling to NF- B. Genes \& development 2004;18(18): 2195-2224.

$\mathrm{He} W$, Liu Q, et al. (2007). TLR4 signaling promotes immune escape of human lung cancer cells by inducing immunosuppressive cytokines and apoptosis resistance. Molecular immunology 44(11): 2850-2859.

Hensler T, Hecker H, Heeg K, Heidecke C, Bartels H, Barthlen W, Wagner H, Siewert J, Holzmann B. Distinct mechanisms of immunosuppression as a consequence of major surgery. Infection and immunity 1997;65(6): 2283.

Holmgren L, O'Reilly M, Folkman J. Dormancy of micrometastases: balanced proliferation and apoptosis in the presence of angiogenesis suppression. Nature Medicine 1995;1(2): 149-153.

Horng T, Barton GM, Medzhitov R. TIRAP: an adapter molecule in the Toll signaling pathway. Nature immunology 2001;2(9): 835-841.

Huang B, Zhao J, Li H, He KL, Chen Y, Chen SH, et al. Toll-like receptors on tumor cells facilitate evasion of immune surveillance. Cancer Res 2005;65:5009-14.

Huang B, Zhao J, Unkeless JC, Feng ZH, Xiong H. (2008) TLR signalling by tumor and immune cells: a double-edged sword. Oncogene 27:218-224.

Jacobi C, Peter F, Wenger F, Ordemann J, Müller J. New therapeutic strategies to avoid intraand extraperitoneal metastases during laparoscopy: results of a tumor model in the rat. Dig Surg 1999;16: 393-399.

Jacobi C, Sabat R, Ordemann J, Wenger F, Volk H, Müller J. Peritoneal instillation of taurolidine and heparin for preventing intraperitoneal tumor growth and trocar 
metastases in laparoscopic operations in the rat model. Langenbecks Archiv für Chirurgie 1997;382(4 Suppl 1): S31.

Jacobs BL, Langland JO. When two strands are better than one: the mediators and modulators of the cellular responses to double stranded RNA. Virology 1996 219:339-349.

Jayne D, Thorpe H, Copeland J, Quirke P, Brown J, Guillou P. Five year follow up of the Medical Research Council CLASICC trial of laparoscopically assisted versus open surgery for colorectal cancer. Br J Surg. 2010 Nov;97(11):1638-45.

Jeung HC, Moon YW, Rha SY, et al. Phase III trial of adjuvant 5-fluorouracil and Adriamycin versus 5-fluorouracil, Adriamycin, and Optimizing Poly(A:U) Anticancer Therapy. Cancer Res; 70(2) January 15, 2010499.

Jones DR, Broad RM, Madrid LV, Baldwin AS, Mayo MW. Inhibition of NFkappaB sensitises non-small cell lung cancer cells to chemotherapy-induced apoptosis, Ann. Thorac. Surg. 70 (2000) 930-936 discussion 936-937.

Karin M, Greten F. NF- B: linking inflammation and immunity to cancer development and progression. Nature Reviews Immunology 2005;5(10): 749-759.

Karin M, Lin A. (2002). NF-B at the crossroads of life and death. Nat. Immunol. 3, 221-27 227.

Kasibhatla, S., Brunner, T., Genestier, L., Echeverri, F., Mahboubi, A., Green, D.R. (1998). DNA damaging agents induce expression of Fas and subsequent apoptosis in $\mathrm{T}$ lymphocytes via the activation of NF-kB and AP-1. Mol. Cell 1, 543-551.

Kelly MG, Alvero AB, Chen R, et al. TLR-4 signaling promotes tumor growth and paclitaxel chemoresistance in ovarian cancer. Cancer Res 2006;66:3859-68.

Khvalevsky E, Rivkin L, Rachmilewitz J, Galun E, Giladi H. TLR3 signaling in a hepatoma cell line is skewed towards apoptosis. J Cell Biochem 2007;100: 1301-12.

Killeen SD, Wang JH, Andrews EJ, Redmond HP (2008) Exploitation of the Toll-like receptor system in cancer: a doubled-edged sword? Br J Cancer 95: 247-252.

Killeen SD, Wang JH, Andrews EJ, Redmond HP. Bacterial endotoxin enhances colorectal cancer cell adhesion and invasion through TLR-4 and NF-kB-dependent activation of the urokinase plasminogen activator system. British Journal of Cancer (2009) 100, $1589-1602$.

Kim R, Emi M, Tanabe K. Cancer immunoediting from immune surveillance to immune escape. Immunology 2007;121(1):1.

Knight B, Skellern G, Smail G, Browne M, Pfirrmann R. NMR studies and GC analysis of the antibacterial agent taurolidine. Journal of Pharmaceutical Sciences 1983;72(6): 705707.

Kuniyasu H, Yasui W, Shinohara H, Yano S, Ellis LM, Wilson MR, Bucana CD, Rikita T, Tahara, E, Fidler I. Induction of angiogenesis by hyperplastic colonic mucosa adjacent to colon cancer. American Journal of Pathology 2000;157:1523-35.

Lacour J, Laplanche A, Malafosse M, Gallot D, Julien M et al. Polyadenylic-polyuridylic acid as an adjuvant in resectable colorectal carcinoma: a $61 / 2$ year follow-up analysis of a multicentric double blind randomized trial. Eur J Surg Oncol. 1992 Dec;18(6):599604.

Laplanche A, Alzieu L, Delozier T, Berlie J, Veyret C, Fargeot P, Luboinski M, Lacour J. Polyadenylic-polyuridylic acid plus locoregional radiotherapy versus chemotherapy with CMF in operable breast cancer: a 14 year follow-up analysis of 
a randomized trial of the F'ed'eration Nationale des Centres de Lutte Contre le Cancer (FNCLCC). Breast Cancer Research and Treatment 64: 189-191, 2000.

Laszlo CF, Wu S. Mechanism of UV-induced IkappaBalpha-independent activation of NFkappaB, Photochem. Photobiol. 84 (2008) 1564-1568

Lee SJ, Lim KT. UDN glycoprotein regulates activities of manganese-superoxide dismutase, activator protein-1, and nuclear factor-kappaB stimulated by reactive oxygen radicals in lipopolysaccharide-stimulated HCT-116 cells. Cancer Lett 2007;254:27487.

Lee Y. Effect of anesthesia and surgery on immunity. Journal of Surgical Oncology 1977;9(5).

Li T, Kaneda Y, Ueda K, Hamano K, Zempo N, Esato K. The influence of tumour resection on angiostatin levels and tumour growth-an experimental study in tumourbearing mice. European Journal of Cancer 2001;37(17): 2283-2288.

Little D, Regan M, BOUCHIER-HAYES D. Perioperative immune modulation. Surgery 1993;114(1): 87-91.

Luo JL, Maeda S, Hsu LC, Yagita H, Karin M. Inhibition of NF- B in cancer cells converts inflammation-induced tumor growth mediated by TNF to TRAIL-mediated tumor regression. Cancer Cell 2004;6(3): 297-305.

Mantovani A. Cancer: Inflammation by remote control, Nature 435 (2005), pp. 752-753.

Marx J. Cancer research: Inflammation and cancer: The link grows stronger. In; 2004. p. 966968.

Matsumoto M, Seya T. TLR3: Interferon induction by double-stranded RNA including poly(I:C). Adv Drug Deliv Rev 2008; 60:805-12.

Meylan, E., K. Burns, K. Hofmann, V. Blancheteau, F. Martinon, M. Kelliher, and J. Tschopp. 2004. RIP1 is an essential mediator of Toll-like receptor 3-induced NF-_B activation. Nat. Immunol. 5:503-507.

Mitchell W. 2006. Review of Ampligen clinical trials in chronic fatigue syndrome. J. Clin. Virol. 37:S113.

Mocellin S, Wang E, Marincola FM. Cytokines and immune response in the tumor microenvironment. J Immunother 2001;24:392-407

MS O, Boehm T, Shing Y, Fukai N, Vasios G, Lane W, Flynn E, Birkhead J, Olsen B, Folkman J. Endostatin: an endogenous inhibitor of angiogenesis and tumor growth. Cell 1997;88(2): 277-285.

Nagai Y, Akashi S, Nagafuku M, Ogata M, Iwakura Y, Akira S, Kitamura T, Kosugi A et al. Essential role of MD-2 in LPS responsiveness and TLR4 distribution. Nat Immunol 3 (2002), pp. 667-672.

Nagorsen D, Keilholz U, Rivoltini L. Schmittel A, Letsch A, Asemissen AM, Berger G, Buhr HJ, Theil E, Scheibenbogen C. Natural T-cell response against MHC class I epitopes of epithelial cell adhesion molecule, her-2/neu, and carcinoembryonic antigen in patients with colorectal cancer. Cancer Res 2000;60:4850-4854.

Okahira S, Nishikawa F, Nishikawa S, Akazawa T, Seya T, Matsumoto M. 2005. Interferonbeta induction through Toll-like receptor 3 depends on double-stranded RNA structure. DNA Cell Biol. 24:614-623.

O'Neill LAJ. The interleukin-1 receptor/Toll-like receptor superfamily: 10 years of progress. Immunological Reviews 2008;226(1):10. 
O'Reilly M, Holmgren L, Shing Y, Chen C, Rosenthal R, Moses M, Lane W, Cao Y, Sage E, Folkman J. Angiostatin: a novel angiogenesis inhibitor that mediates the suppression of metastases by a Lewis lung carcinoma. Cell 1994;79(2): 315-328.

Penn I. Post-transplant malignancy: the role of immunosuppression. Drug Saf 2000;23:101113.

Pidgeon G, Harmey J, Kay E, Da Costa M, Redmond H, Bouchier-Hayes D. The role of endotoxin/lipopolysaccharide in surgically induced tumour growth in a murine model of metastatic disease. British journal of cancer 1999;81(8): 1311-1317.

Pikarsky E, Porat RM, Stein I, Abramovitch R, Amit S, Kasem S, Gutkovich-Pyest E, UrieliShoval S, Galun E, Ben-Neriah Y. NF- B functions as a tumour promoter in inflammation-associated cancer. Nature 2004;431(7007): 461-466.

Rakoff-Nahoum S, Medzhitov R. Regulation of spontaneous intestinal tumorigenesis through the adaptor protein MyD88. Science 2007;317(5834):124.

Reith H. Therapy of peritonitis today. Surgical management and adjuvant therapy strategies. Langenbecks Archiv für Chirurgie 1997;382(4 Suppl 1): S14.

Rithidech KN, Tungjai M, Arbab E, Simon SR. Activation of NF-kappaB in bone marrow cells of BALB/cJ mice following exposure in vivo to low doses of (137)Cs gammarays, Radiat. Environ. Biophys. 44 (2005) 139-143.

Rollins B. Inflammatory chemokines in cancer growth and progression. European Journal of Cancer. 2006;42:760-7.

Rosenberg SA. Progress in human tumour immunology and immunotherapy. Nature 2001;411:380-384.

Ryder NM, Guha S, Hines OJ, Reber HA, Rozengurt E. G protein-coupled receptor signaling in human ductal pancreatic cancer cells: neurotensin responsiveness and mitogenic stimulation. J Cell Physiol 2001; 186: 53-64.

Salaun B, Coste I, Rissoan MC, Lebecque SJ, Renno T. TLR3 can directly trigger apoptosis in human cancer cells. J Immunol 2006; 176: 4894-901.

Salaun B, Lebecque S, Matikainen S, Rimoldi D, Romero P. Toll-like receptor 3 expressed by melanoma cells as a target for therapy? Clin Cancer Res 2007;13: 4565-74.

Schulz O, Diebold SS, Chen M, et al. Toll-like receptor 3 promotes cross-priming to virusinfected cells. Nature 2005;433:887-92.

Seckl MJ, Higgins T, Widmer F, Rozengurt E. [DArg1,D-Trp5,7,9,Leu11]substance P: a novel potent inhibitor of signal transduction and growth in vitro and in vivo in small cell lung cancer cells. Cancer Res 1997:57;51-4

Seliger B, Wollscheid U, Momburg F, Blankenstein T, Huber C. Characterization of the major histocompatibility complex class I deficiencies in B16 melanoma cells. Cancer Res 2001;61:1095-1099

Sen R, Baltimore D. Inducibility of kappa immunoglobulin enhancer-binding protein Nfkappa B by a posttranslational mechanism. Cell 1986;47(6): 921-928.

Shankaran V, Ikeda H, Bruce A, White J, Swanson P, Old L, Schreiber R. IFN and lymphocytes prevent primary tumour development and shape tumour immunogenicity. Nature 2001;410(6832): 1107-1111.

Shimazu R, Akashi S, Ogata H, Nagai Y, Fukudome K, Miyake K, Kimoto M. MD-2, a molecule that confers lipopolysaccharide responsiveness on Toll-like receptor 4 . J Exp Med 189 (1999), pp. 1777-1782. 
Stark GR. How cells respond to interferons revisited: from early history to current complexity. Cytokine Growth Factor Rev 2007; 18: 419-23.

Sun Q, Zheng Y, Liu Q, Cao X. International Immunopharmacology 8 (2008) 1854-1858.

Tabiasco J, Devevre E, Rufer N, et al. Human effector CD8+ T lymphocytes express TLR3 as a functional coreceptor. J Immunol 2006;177:8708-13.

Takeuchi, M. Sugiyama, M. Okabe, K. Takeda, and S. Akira. 2003. Role of adaptor TRIF in the MyD88-independent Toll-like receptor signaling pathway. Science 301:640-643.

Taura M, Eguma A, Suico MA et al. p53 regulates Toll-like receptor 3 expression and function in human epithelial cell lines. Mol Cell Biol 2008; 28: 6557-67.

Taura M, Fukuda R, Suico MA, Eguma A, Koga T et al. TLR3 induction by anticancer drugs potentiates poly I:C-induced tumor cell apoptosis. Cancer Sci | July 2010 | vol. 101 | no. 7 | 1615

Thompson KA, Strayer DR, Salvato, PD, Thompson CE, Klimas N, Molavi A et al. Results of a double blinded placebo controlled study of the double stranded RNA drug poly1:polyC12U in the treatment of HIV infection. Eur J Clin Microbiol Infect Dis 1996;15(7):580-7.

Uetsuka H, Haisa M, Kimura M, Gunduz M, Kaneda Y et al. Inhibition of inducible NFkappaB activity reduces chemoresistance to 5-fluorouracil in human stomach cancer cell line, Exp. Cell Res. 289 (2003) 27-35.

Vercammen E, Staal J, Beyaert R. Sensing of Viral Infection and Activation of Innate Immunity by Toll-Like Receptor 3. CLINICAL MICROBIOLOGY REVIEWS, Jan. 2008, p. 13-25 Vol. 21, No. 1.

Wadler S, Schwartz EL. Antineoplastic activity of the combination of interferon and cytotoxic agents against experimental and human malignancies: a review. Cancer Res 1990; 50: 3473-86.

Walker C, Bruce D, Heys S, Gough D, Binnie N, Eremin O. Minimal modulation of lymphocyte and natural killer cell subsets following minimal access surgery. American journal of surgery 1999;177(1): 48.

Walker PR, Saas P, Dietrich PY. Role of Fas ligand (CD95L) in immune escape: the tumor cell strikes back. J Immunol 1997;158:4521-4524

Wang EL, Qian ZR, Nakasono M, Tanahashi T, Yoshimoto K, Bando Yet al. High expression of Toll-like receptor 4 /myeloid differentiation factor 88 signals correlates with poor prognosis in colorectal cancer. British Journal of Cancer (2010) 102, 908 - 915.

Wang L, Liu Q, Sun Q, Zhang C, Chen T, Cao X. TLR4 signaling in cancer cells promotes chemoattraction of immature dendritic cells via autocrine CCL20. Biochem Biophys Res Commun 2008;366:857-61.

Wang WH, Huang JQ, Zheng GF, Lam SK, Karlberg J, Wong BCY. Non-steroidal antiinflammatory drug use and the risk of gastric cancer: a systematic review and meta-analysis. jnci 2003;95(23): 1784-1791.

Warzocha K, Ribeiro P, Bienvenu J, Roy P, Charlot C, Rigal D, Coiffier B, Salles G. Genetic polymorphisms in the tumor necrosis factor locus influence non-Hodgkin's lymphoma outcome. Blood 1998;91(10): 3574.

Wiemann B, Starnes CO. Coley's toxins, tumor necrosis factor and cancer research: a historical perspective. Pharmacol Ther. 1994;64(3):529-64. 
Yakovlev VA, Barani IJ, Rabender CS, Black SM, Leach JK et al. Tyrosine nitration of IkappaBalpha: a novel mechanism for NF-kappaB activation. Biochemistry 46 (2007) 11671-11683.

Yamamoto M, Sato S, Hemmi H, Hoshino K, Kaisho T, Sanjo H, Takeuchi O, Sugiyama M, Okabe M, Takeda K, Akira S. Role of adaptor TRIF in the MyD88-independent tolllike receptor signaling pathway. Science. 2003 Aug 1;301(5633):640-3.

Yang T, McNally BA, Ferrone S, Liu Y, Zheng P. A single-nucleotide deletion leads to rapid degradation of TAP-1 mRNA in a melanoma cell line. J Biol Chem 2003;278:1529115296

Yoneyama M, Kikuchi M, Natsukawa T, Shinobu N, Imaizumi T, Miyagishi M, et al. The RNA helicase RIG-I has an essential function in double-stranded RNA-induced innate antiviral responses. Nat Immunol 2004; 5:730-7.

Zhang JF, Liu JJ, Lu MQ, Cai CJ, Yang Y, Li H, et al. Rapamycin inhibits cell growth by induction of apoptosis on hepatocellular carcinoma cells in vitro. Transpl Immunol 2007;17:162-8.

Zhu YM, Webster SJ, Flower D, Woll PJ. Interleukin-8/CXCL8 is a growth factor for human lung cancer cells. British Journal of Cancer (2004) 91, 1970 - 1976. 


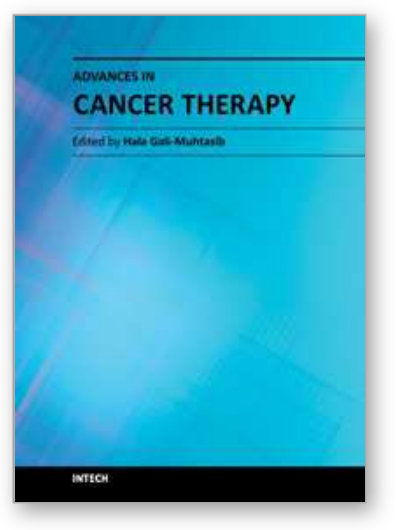

\author{
Advances in Cancer Therapy \\ Edited by Prof. Hala Gali-Muhtasib
}

ISBN 978-953-307-703-1

Hard cover, 568 pages

Publisher InTech

Published online 21, November, 2011

Published in print edition November, 2011

The book "Advances in Cancer Therapy" is a new addition to the Intech collection of books and aims at providing scientists and clinicians with a comprehensive overview of the state of current knowledge and latest research findings in the area of cancer therapy. For this purpose research articles, clinical investigations and review papers that are thought to improve the readers' understanding of cancer therapy developments and/or to keep them up to date with the most recent advances in this field have been included in this book. With cancer being one of the most serious diseases of our times, I am confident that this book will meet the patients', physicians' and researchers' needs.

\title{
How to reference
}

In order to correctly reference this scholarly work, feel free to copy and paste the following:

O'Leary D.P., Neary P.M. and Redmond H.P. (2011). The Role of Inflammation in Cancer, Advances in Cancer Therapy, Prof. Hala Gali-Muhtasib (Ed.), ISBN: 978-953-307-703-1, InTech, Available from:

http://www.intechopen.com/books/advances-in-cancer-therapy/the-role-of-inflammation-in-cancer

\section{INTECH}

open science | open minds

\section{InTech Europe}

University Campus STeP Ri

Slavka Krautzeka 83/A

51000 Rijeka, Croatia

Phone: +385 (51) 770447

Fax: +385 (51) 686166

www.intechopen.com

\section{InTech China}

Unit 405, Office Block, Hotel Equatorial Shanghai

No.65, Yan An Road (West), Shanghai, 200040, China

中国上海市延安西路65号上海国际贵都大饭店办公楼 405 单元

Phone: +86-21-62489820

Fax: +86-21-62489821 
(C) 2011 The Author(s). Licensee IntechOpen. This is an open access article distributed under the terms of the Creative Commons Attribution 3.0 License, which permits unrestricted use, distribution, and reproduction in any medium, provided the original work is properly cited. 